\title{
Exchange Rate Volatility, Global Market Exposure and Operational Efficiency among US Commercial Banks
}

\author{
Rexford Abaidoo ${ }^{1}$ \\ ${ }^{1}$ School of Business and Technology, University of Maryland Eastern Shore, USA \\ Correspondence: Rexford Abaidoo, School of Business and Technology, University of Maryland Eastern Shore, \\ USA. E-mail: rabaidoo@umes.edu
}

Received: June 5, 2014

Accepted: June 19, 2014

Online Published: August 25, 2014

doi:10.5539/ijef.v6n9p83

URL: http://dx.doi.org/10.5539/ijef.v6n9p83

\begin{abstract}
This study investigates how specific macroeconomic conditions/variables influence operational efficiency dynamics among US Commercial banks at the aggregate level. Empirical approach adopted in this study examines both the short and long run effects of modeled explanatory variables on operational efficiency. Utilizing net interest margin as a proxy for operational efficiency among US commercial banks, short and long run effects of modeled macroeconomic conditions/variables on bank operational efficiency are estimated. Ensuing empirical results show that conditions such as macroeconomic uncertainty, exchange rate volatility, global market exposure etc. have significant and varying impact on operational efficiency among US commercial banks in both the short and the long run. For instance, this study finds that macroeconomic uncertainty has negative impact on operational efficiency among US commercial banks in the short run; the effect however, tends to dissipates in the long run. Test estimates further suggest that exchange rate volatility rather augments operational efficiency among these commercial banks in both the short and long run; whereas financial liberalization restricts growth in operational efficiency.
\end{abstract}

Keywords: bank operational efficiency, exchange rate volatility, macroeconomic uncertainty, ADL model

\section{Introduction}

In a dynamic macroeconomic environment, operational principles guiding most financial institutions such as Commercial banks, tend to revolve around key objectives such as; the need to remain competitive in an evolving financial environment, and continual efforts to meet specific performance markers consistent with market and shareholder expectations. This relentless expectation for consistent and appreciable performance among financial institutions, (often in the midst of highly competitive and sometimes volatile macroeconomic environment) has occasioned, and continues to foster the need for periodic performance assessment. Among financial institutions, a well-defined periodic performance assessment process, offers the platform to monitor performance targets against projected or critical performance indicators and institutional objectives. For most financial institutions, this ongoing need to achieve core operational objectives has become integral part of structured periodic organizational performance monitoring and evaluation framework, meant to periodically track potential deviations from key performance benchmarks and objectives. Evidence of growing importance of this performance monitoring and evaluation process can be found in legion of existing literature focusing on financial institutions and bank performance (to be reviewed in subsequent sections). This study among other things seeks to verify the extent to which specific macroeconomic variables or conditions influence aggregate performance variability among US commercial banks; however, unlike related studies found in the literature, performance in this empirical estimation is defined in terms of operational efficiency instead of profitability and other related measures found in the present literature.

A review of the literature focusing on performance dynamics among financial institution such commercial banks, suggests that variability in performance dynamics among such institutions revolves around two broadly defined factors; Institutional or operational specific factors which dominates the literature, and external macroeconomic conditions integral to the operations of such financial institutions. This dual performance defining feature, suggest that among financial institutions, forecasted or projected performance targets tend to revolve around core industry/ internal operational characteristics as well as external macroeconomic conditions or policy induced factors (Demirgüç-Kunt \& Huizinga, 1999). This view that performance features among financial institutions are 
define by two broad factors, makes the case for holistic approach to institutional performance assessment as opposed to partial empirical analysis often found in the literature. Although a holistic approach to institutional performance assessment is the preferred approach for most financial institutions given the reason already articulated, it is important however, to point out that a strong case has been made over the years for the rational to pursue partial approach to institutional performance assessment. For instance, it has been argued that a partial approach to institution performance assessment focusing on only institutional specific factors is sometimes necessary when the objective is to assess the sole impact of such factors holding constant, moderating effect of external macroeconomic factors or conditions. This fundamental view that observed variability in performance among financial institutions tend to reflect both institutional specific and external macroeconomic factors, forms the basis for some of the empirical assessment made in this study.

\subsection{Uniqueness of this Study's Approach}

This study's approach to performance assessment among financial institutions differs from similar studies found in the literature (Note 1) on dynamics of bank performance; which, is dominated by how firm/industry specific factors such as size, type of ownership, degree of market concentration etc. impact profitability. Instead of these industry specific factors, this study evaluates how specific macroeconomic factors and other conditions in the broader business environment, impact aggregate operational efficiency among US Commercial banks. Another distinctive feature between this study's approach and related studies alluded to earlier, hinges on the type of performance assessment parameter employed. Unlike most existing studies focusing on bank performance, this study opt for net interest margin (NIM), as a measure of aggregate operational efficiency among US Commercial Banks instead of profitability measures such as (ROA), (ROE), economic value added (EVA) etc. NIM parameter is preferred in this study instead of traditional profitability measures of performance because this study seeks to define performance in terms of operational efficiency and not profitability. The approach is also meant to verify if employing different performance assessment parameter based on operational efficiency, significantly alters the extent to which modeled macroeconomic factors impact aggregate performance among US commercial banks. Operational efficiency parameter (NIM) adopted in this study measures how well commercial banks manage assets and liabilities with particular emphasis on the spread between interest earned on its assets and the cost on its liabilities. Using this measure, commercial banks having assets with high interest return, and liabilities which attracts low interest cost are deemed to exhibit relatively high operational efficiency; which all things being equal, enhances the likelihood for significant growth in profits and vice versa. Finally, this study's approach also adds to ongoing discussion on bank performance by introducing and testing for the effects of conditions or factors whose impact on aggregate operational efficiency among commercial banks are yet to be verified according to reviewed literature.

This study, therefore focuses primarily on determining the extent to which specific macroeconomic conditions impact operational efficiency among US commercial banks using Net Income Margin as a measure of aggregate operational efficiency. Empirical tests to be conducted in this study will not necessarily require controls for industry specific or internal factors in that, operational efficiency parameter employed in the estimation process uses aggregate level data; which eliminates the need for controlling for bank specific characteristics or features unique to individual banks. The remainder of this study is organized as follows; a succinct review of some of the methods used in estimating bank performance or profitability is conducted; followed by analysis of aggregate performance of US commercial banks via NIM approach. Section three reviews the literature on determinants of bank performance highlighting how both industry specific and macroeconomic factors influence bank performance across studies. Type and sources of data employed in the study are also stated; and this is followed by specification of empirical model and other econometric procedures critical in assessing how modeled explanatory variables explains variability in aggregate operational efficiency among US commercial banks. The final section of the study estimates both short and long run elasticity of key explanatory variables using error correction process; analysis of the results of this empirical estimation will then inform conclusions and policy recommendations made at the end of this study.

\section{The Case for NIM as a Measure of Aggregate Operational Efficiency}

The ever-expanding literature focusing on dynamics of bank performance provides legion of performance indicators designed to verify the extent to which financial institutions such as commercial banks assess defined performance indicators. Examination of this literature show that performance measures such as Return on Assets (ROA), which captures profitability of financial institutions or banks relative to total assets under management dominates the literature on bank performance. Studies such as Ben Naceur and Goaied (2008), Kosmidou (2008), and Abbasoglu, Aysan and Gunes (2007) were all based on this parameter as a measure of bank performance. In most of these studies, ROA ratio parameter was used to estimate how management of banks or financial 
institutions maximizes earnings given total assets under their control. Return on Equity (ROE), another ratio parameter often employed in estimating bank performance overtime; on the other hand measures bank profitability by estimating profit such banks generates with shareholders investments. Economic Value Added (EVA), another performance ratio parameter found in the literature, and featured in studies such as Stouhgton and Zechner (2007) and Millar (2005) etc. has also been used significantly in estimating bank performance.

However, unlike these noted traditional performance assessment parameters which focuses predominantly on profitability, this study rather focuses on operational efficiency utilizing net Interest Margin (NIM) performance ratio. This performance ratio (NIM), examines operational efficiency associated with how commercial banks manage resource under their control. Stated differently, NIM assesses performance on interest income generated by commercial banks on assets under management, relative to income paid as interest on debt etc.. Using NIM as a measure of bank operational efficiency has some basis in existing literature. According to Vansel et al (2004), apart from being a good measure of general bank performance, NIM could also be modeled as a good proxy for bank's operational efficiency; in that, the ratio, estimates how management efficiently balance return on assets and cost of debt over time. This study, consequently, focuses on this operational efficiency feature of NIM ratio in its analysis of how specific macroeconomic conditions or factors impact aggregate operational efficiency among US commercial banks.

\section{Operational Efficiency (NIM) Characteristics of US Commercial Banks (1984-2013)}

Like most financial institutions around the world, US Commercial Banks continue to reinvent themselves as they navigate through ever-evolving macroeconomic conditions and plethora of regulatory frameworks meant to ensure financial and economic stability. For instance, apart from occasional variability in domestic and global macroeconomic conditions which significantly impact operations, US Commercial Banks have to also adapt to changing regulatory policies such as, safety and soundness regulations, credit allocation regulations, consumer protection regulations, monetary policy regulations etc. that are integral to their operations. Regulatory policies such as the Dodd-Frank Wall Street Reform Act and Consumer Protection Act which were meant to "promote financial stability through accountability and transparency, for instance, further placed additional operational burden on US commercial banks. However, despite these regulatory maze and macroeconomic conditions that these banks have to carefully navigate, available aggregate quarterly data on operational efficiency (NIM) among US Commercial Banks show appreciable trend performance. The data show that on average, these financial institutions have, and continue to perform relatively well operationally; sometimes even exceeding market expectations. Figure 1 charts aggregate operational efficiency performance (NIM) among US commercial banks over the period under consideration; and show that operationally, US commercial banks have performed better over the period under study. Trend characteristics depicted in figure 1, for instance, suggest that, although the 2008 recession led to some decline in operational efficiency, (indicated by minor decline over the 2008-2009 period), the sharp decline in economic activity over the period did not lead to drastic decline in operational efficiency among US commercial banks. Figure 1 suggests operational efficiency among US commercial banks over the period under study fluctuated well over three percent.

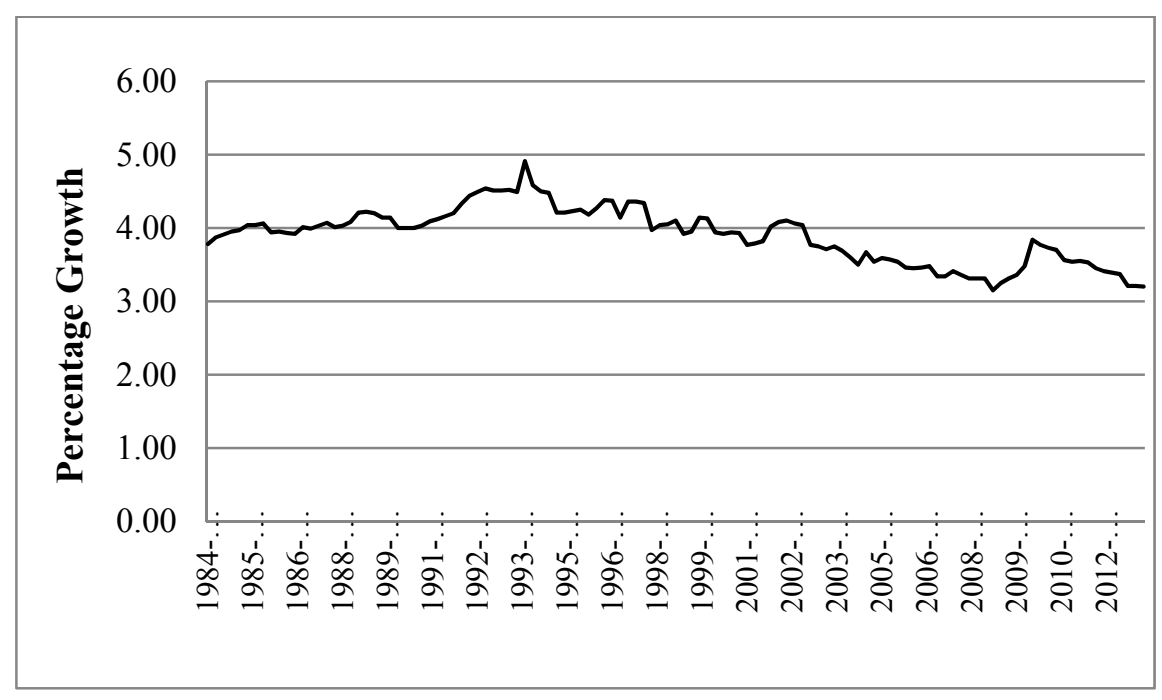

Figure 1. Quarterly NIM growth 


\section{Determinants of Bank Performance-The Literature}

This study's assessment of how specific conditions/factors impact operational efficiency among US commercial banks hinges on the assumption that the main objective of such banks revolves around achieving operational efficiency and profitability consistent with shareholders expectations. Like most financial and non-financial institutions however, US commercial banks are confronted with a constrained optimization problem. These institutions seeks to maximize shareholders' equity (profitability etc.) and remain competitive in an evolving financial environment subject to industry specific constraints/factors, and external macroeconomic vicissitudes. The view that operational efficiency among commercial banks to a large extent, is define by underlying bank specific/internal factors as well as external macroeconomic conditions is supported by significant empirical studies focusing on bank performance. For instance, in a related study focusing on the dynamics of bank performance, Toddard et al. (2004) and Panayiotis et al. (2005) showed that bank profitability (performance) is a function of associated internal or bank specific as well as external macroeconomic factors. This dual approach to assessing bank performance dominates the literature on determinants of bank performance. Giving this background, this study's review of determinants of bank performance, adopt similar trend by analyzing external/macroeconomic and industry specific factors shown to explain variability in bank performance in existing literature. The following sub-sections review internal/industry specific and external macroeconomic factors shown to impact bank performance.

\subsection{Bank/industry Specific Factors Explaining Performance Variability}

Bank or industry specific performance moderating factors refers to operational features or characteristics unique to the banking sector; which are shown to impact profitability or performance. A review of this strand of literature on determinants of bank performance provides a number of factors or features found to explain variability in bank performance or profitability. While a segment of the literature emphasize importance of features such as size, type of control, market share etc. as core bank specific factors explaining bank performance heterogeneities, other studies under the same strand of literature point to the role of management efficiency and internal risk management capacity etc., as key factors defining bank performance dynamics. For instance, Filbeck et al. (2011) submitted that bank size play significant role in performance during periods of economic contraction. Barros, Ferreira and Williams (2007), further showed that small banks are more likely to perform better than their larger counterparts. Again, Pasiouras and Kosmidou (2007) also found that bank size tend to have significant impact on performance. Stiroh and Rumble (2006), further surmised that bank size have significant impact on performance in their study. In a related literature, Kasman (2010) additionally showed that size and managerial efficiency tend to have significant negative impact on net interest margin among banks. Athanasoglou et al. (2005) also concluded that industry specific factors such as bank size, capital, management efficiency and risk management capacity are the key determinants of bank performance. In a similar analysis focusing how the form of control impact bank performance, Micco, Panizza and Yanez (2007) also showed that the type of control exercised over bank's operational activities has significant impact on performance. Among developing economies for instance, Micco, Panizza and Yanez's study, found that nationalized banks tend to perform poorer with low margins and relatively high operational cost compared to private banks.

In a related study focusing on bank performance, Dietrich and Wanzenried (2011) who analyzed similar performance conditions in Switzerland, also found evidence consistent with submissions made by Micco, Panizza and Yanez (2007); that, nationalized banks are less efficient than private banks. Again, in another study focusing on factors explaining heterogeneity in bank performance in Japan, Liu and Wilson (2010), further concluded that there exist significant negative relationship between market share and bank performance, regardless of the type of bank. Molyneux and Thornton (1992) in an earlier study also concluded that bank concentration ratio has positive and statistically significant impact on performance. Dietrich and Wanzenried (2011) further suggest that diversification has positive effect on bank performance; a conclusion which supports core financial principle suggesting that highly diversified firms tend to face relatively reduced risk threshold which significantly increase potential for appreciable performance. These reviewed studies suggest that, at the disaggregated level, significantly varied bank specific features or characteristics play vital role in determining performance over time. It further lend credence to the view that performance heterogeneity among banks tend to revolve around diametrically varied bank or industry specific characteristics; and that a feature which might augments one bank's performance might rather be inimical to another bank's prospect of meeting performance targets due to other moderating conditions or factors.

\subsection{Macroeconomic Factors or Conditions Explaining Bank Performance Variability}

Apart from industry and bank specific features or characteristics discussed above, significant empirical studies 
also exist suggesting that ultimately, the macroeconomic environment within which such banks operate, also has significant impact on performance. As key financial actors channeling financial resources to various sectors of the economy, operational activities of banking institutions have been shown to be influenced by prevailing macroeconomic dynamics and other external factors. Reviewed empirical evidence suggests that macroeconomic performance and trend conditions associated with key economic indicators have significant impact on bank performance. For instance, in an earlier study focusing on the relationship, Afanasieff, Lhacer and Nakane (2002) concluded that inflationary conditions have negative impact on net interest margins; this conclusion supported earlier findings by Saunders and Schumacher (2000) in a related analysis. Additionally, in a recent study verifying similar relationship among Tunisian deposit banks, Ayadi and Boujelbene (2012) also showed that Inflationary conditions have negative impact on profitability among banks studied. Schwaiger and Liebig (2008) further made a strong case for the role of macroeconomic conditions by showing that banks perform better in periods of significant growth characterized by relatively high investment and consumption growth, and growth in credit supply. This condition suggests that favorable macroeconomic conditions, tends to have positive impact on bank performance. Bikker and $\mathrm{Hu}$ (2002) in an earlier study also established that bank profits correlates positively with movements in the business cycles. A study by Allen and Saunders (2004), further provided empirical evidence in support of the importance of macroeconomic factors or conditions in determining bank profitability. These reviewed studies to a greater extent support the general view of positive association between economic performance (growth) and bank profitability. However, in a study focusing on a similar relationship among Sub-Saharan African economies, Al-Haschimi (2007) who employed net interest margin as a measure of performance, concluded that macroeconomic factors, have much less influence on bank performance than other studies have suggested. Again, Sufian and Razali (2008) whose study focused on bank profitability in the Philippines also indicated that not all macroeconomic variables are significant in bank performance; the study found that specific variables/conditions such as money supply and stock market capitalization have insignificant impact on bank performance.

\section{Data Source and Variables}

Net Interest Margin (NIM), this study's proposed measure of operational efficiency among US commercial banks, is the main dependent variable in this study. This variable is projected to capture how effective US commercial banks are in their operations. External or macroeconomic factors whose impacts on operational efficiency among commercial banks are being verified, on the other hand, include exchange rate volatility (Exvol), and financial liberalization (Finlib) modeled as the ratio of broad money to GDP growth (M2/GDPg). Financial liberalization variable (Finlib), in this study, is modeled to capture conditions such as interest rate deregulation; credit control removal, and liberalization of restrictions or policies meant to ensure stability in the financial system. Global market exposure $(G M E)$, another explanatory variable in this study, proxied by net exports contribution to GDP growth, is meant to capture degree of exposure or integration of US commercial banks into the global financial system. This study also test for the effect of macroeconomic uncertainty (Munc) in general on operational efficiency among US commercial banks using a generalized autoregressive conditional heteroscedastic (garch) process based on US economic performance (GDP growth). The rest of the independent variables tested in this study include GDP growth $(G D P g)$, Inflation expectations (Infexp), and Inflation rate (Infl). Data on these listed variables are sourced from St. Louis Fed Database (FRED) and US Bureau of Economic Analysis (BEA). All variables are made up of quarterly time series spanning the year 1984 to 2013.

\section{Empirical Framework}

\subsection{Model Specification}

To estimate the extent to which modeled external factors or macroeconomic conditions influence variability in aggregate operational efficiency among US commercial banks, this study propose a linear framework as the basis from which subsequent econometric analysis would be made. The following linear equation summarizes projected relationship between operational efficiency among US commercial banks and modeled explanatory variables:

$$
\Pi_{t}=a_{1}+a_{2} y_{1}+a_{3} m_{t}+a_{4} \lambda_{1}+a_{5} \psi_{1}+a_{6} \delta_{1}+a_{7} \mu_{1}+a_{8} \pi+e_{t}^{y}
$$

Where:

$\Pi_{t}=$ Aggregate operational efficiency among commercial banks measured by (NIM);

(y) Munc $_{t}=$ Macroeconomic uncertainty parameter derived using (garch) process;

(m) $\operatorname{InfExp} p_{t}=$ Inflation expectations (projected persistent increase in price levels); 
(ג) Exvol $_{t}=$ Exchange rate fluctuations derived using (garch) process;

( $\psi)$ Finlib $_{t}=$ Financial liberalization;

( $\delta)$ Infl $_{t}=$ inflation rate;

( $\mu$ ) $G M E_{t}=$ Global Market Exposure;

( $\pi) \mathrm{GDPg}_{t}=$ Economic Performance;

$e_{t}^{y}=$ Random error term assumed independent and identically distributed (iid).

Using linear framework proposed in equation (1), this study estimates how modeled explanatory variables influence operational efficiency among US commercial bank using an error correction process. This empirical framework test short and long run dynamics of bank operational efficiency via cointegration analysis. Modelling process involved in this analysis, is achieved through autoregressive process using modified autoregressive distributed lag model (ADL). This study opted for the ADL framework because of verified empirical advantages compared to similar methods found in the literature. The ADL framework for instance, has been shown to yield significant results regardless of the order of integration of variables in treatment; (i.e., whether explanatory variables are I(0), I(1), or mutually cointegrated); Pesaran et al. (2001). Again, according to Alam and Quazi (2003), the ADL framework tends to yield robust estimates even in instances when explanatory variables in treatment are endogenous. These features, together makes the ADL framework ideal for analysis conducted in this study. To test for cointegrating or long run relationship between operational efficiency and stated explanatory variables, this study employs bounds test critical values proposed by Narayan (2004). The choice of this bounds test critical values over those often used in the literature has been informed by reported empirical findings suggesting that critical bound values suggested by Narayan (2004) are more accurate for small sample data sets $(<500)$ compared to those propounded by Pasaran et al (2001) which is more suited for relatively large sample tests.

Following empirical framework similar to that employed in Ahmed Imtiaz and Qayyum Abdul (2007), effects of modeled macroeconomic conditions on operational efficiency among US commercial banks using autoregressive distributed lagged technique could be reformulated from equations (1) as follows:

$$
Z_{t}=\pi+\Pi_{l} Z_{t-1}+\Pi_{2} Q_{t-2}+\ldots+\Pi_{k} Q_{t-k}+\mu_{t}
$$

Where $Z_{t}$ defines vector of dependent variable in the study, and $Q$ a vector of independent variables projected to explain variability in aggregate operational efficiency among commercial banks; namely, macroeconomic uncertainty, financial liberalization, inflation expectations, inflation, exchange rate fluctuations and GDP growth. $\pi$, captures the vector of the constant term, and $\mu_{\mathrm{t}}$, the error or disturbance term assumed to be (iid) with $\left(0, \sigma^{2}\right)$. This study employs equation (2) in estimating long run relationship between modeled regressors and operational efficiency among US commercial banks.

To estimate similar effects in the short run, a difference notation denoted as $\Delta=1-\mathrm{L}$ is first defined; where $\mathrm{L}$ defines a lag operator. Using this notation, dynamic error correction model $(E \mathrm{~cm})$ estimating short run effects of stated explanatory variables on aggregate operational efficiency among US commercial banks can be modeled as follows:

$$
\Delta Z_{t}=\pi+\sum_{i=1}^{p-1} \Gamma_{i} \Delta Z_{t-i}+\Pi Q_{t-k}+(E c m)_{t-1}+\mu_{t-k}
$$

From equation 3, the error correction function $(E \mathrm{~cm})$, can then be derived as:

$$
(\text { Ecm })_{t-1}=\Delta Z_{t}-\pi-\sum_{i=1}^{p-1} \Gamma_{i} \Delta Z_{t-i}-\Pi Q_{t-k}-\mu_{t-k}
$$

Where: $\Gamma_{i}=-\left(\mathrm{I}-\Pi_{l^{-}} \ldots-\Pi i\right), E c m=$ error correction parameter, and $i=1,2,3, \ldots, k-1$.

Error correction model in equation (3), in this instance, estimates how employed explanatory variables impact operational efficiency among commercial banks in the short run whereas equation (4) captures the speed of adjustment towards equilibrium from short run deviations or distortions.

\section{Modeling Exchange Rate Volatility and Macroeconomic Uncertainty}

Among the explanatory variables employed in this study, exchange rate volatility and macroeconomic uncertainty variables have to be derived from some based indicators or variables. These base variables have to go through further treatment in order to capture conditions whose impact on operational efficiency is being estimated. To derived macroeconomic uncertainty and exchange rate volatility variables from base 
indicators or variables, this study employs conditional variance in a generalized autoregressive conditional heteroskedastic framework $\operatorname{GARCH}(1,1)$; a model propounded by Bollerslev (1986) as a generalization of Engle (1982) ARCH framework. This econometric process allows us to capture fluctuations inherent in specific variables in treatment such GDP growth in the case of macroeconomic uncertainty; where persistent fluctuations in GDP growth have been shown to induce significant measure of uncertainty among economic agents. Using this econometric procedure $(\mathrm{GARCH})$, the two variables are derived using the following equation:

$$
h_{t}=\omega+\alpha h_{t-1} \varepsilon_{t-1}^{2}+\beta h_{t-1}
$$

Where, $h_{t}$ captures fluctuations in exchange rate, and GDP growth respectively.

\subsection{Bound Test for Cointegration Analysis}

Cointegration or long run relationship estimates discussed in this section adopts critical bound values proposed by Narayan (2004) as stated earlier. Bound test for cointegration technique verifies long run relationship using F-test statistic procedure. This diagnostic procedure verifies long run relationship by comparing F-test statistic of subsequent regression results, and adopted critical bound values at $1 \%, 5 \%$ and $10 \%$ significance level respectively. Hypothesized condition of long run relationship in this case is accepted if resultant F-test statistic exceeds critical bound values at the various noted levels of significance, and vice versa. The null hypothesis of an existence of $\sigma$ cointegration vector(s) against condition of non-existence of such vector(s) $\tau$. is tested as follows:

$$
H_{0}:(\Pi)=\sigma \text { Against the alternative hypothesis } H_{1}:(\Pi)=\tau
$$

Test for cointegrating relationship between modeled explanatory variables and aggregate operational efficiency among US commercial banks using stated approach, found existence of significant conintegrating relationship at $10 \%$ alpha level. This conclusion is based on computed F-test statistic of 3.46 and critical bound values sourced from Narayan (2004); under Case II, with restricted intercept and no trend; and $\mathrm{k}=7$. With a form of cointegration relationship established between modeled explanatory variables and operational efficiency, the following section provides detailed tests for short and long run effects of stated variables on aggregate operational efficiency among US commercial banks.

\subsection{Macroeconomic Conditions and External Determinants of Bank Operational Efficiency}

Table 1 report coefficient estimates of short and long run effects of modeled macroeconomic variables on aggregate operational efficiency among US commercial banks using error correction framework. Reported coefficient estimates in table 1 suggest that the extent to which modeled variables or conditions impact operational efficiency among US commercial banks diverge significantly in the short and long run. In the following subsections, a thorough analysis of estimated short and long relationships between stated explanatory variables and aggregate operational efficiency based on table 1 are discussed.

Table 1. Short and long run effects of modeled macroeconomic variables

\begin{tabular}{ccc}
\hline Variables & Short Run Dynamics & Long Run Dynamics \\
\hline Munc $_{t}$ & $-0.0899^{* * *}$ & -0.1670 \\
& $(0.0272)$ & $(0.1050)$ \\
nfExp & -0.0089 & -0.0633 \\
& $(0.0272)$ & $(0.0508)$ \\
Exvol $_{t}$ & $0.0231^{* *}$ & $0.0511^{* *}$ \\
& $(0.0121)$ & $(0.0213)$ \\
Finlib $_{t}$ & $-0.00154^{* *}$ & $-0.0073^{* *}$ \\
& $(0.0009)$ & $(0.0033)$ \\
Infl $_{t}$ & 0.0102 & $0.1130^{* *}$ \\
& $(0.0184)$ & $(0.0614)$ \\
GME $_{t}$ & -0.0133 & $-0.0614^{* *}$ \\
& $(0.0098)$ & $(0.0315)$ \\
GDPg & $0.0329^{* *}$ & 0.1950 \\
& $(0.0168)$ & $(0.121)$ \\
NIM & -0.1030 & -1.330 \\
& $(0.0931)$ & $(0.796)$ \\
Cons & -0.0050 & 5.000 \\
\hline
\end{tabular}




\begin{tabular}{|c|c|c|c|}
\hline & $(0.0099)$ & & $(3.1010)$ \\
\hline Stand errors in parentheses & $* \mathrm{p}<0.1$ & $* * \mathrm{p}<0.05$ & $* * * \mathrm{p}<0.01$ \\
\hline$N$ & 116 & & 116 \\
\hline$R-s q$ & 0.125 & & 0.152 \\
\hline
\end{tabular}

\subsubsection{Operational Efficiency among US Commercial banks and Macroeconomic Conditions: Short Run Analysis}

Coefficients estimates verifying how stated explanatory variables explains variability in operational efficiency among commercial banks, suggest that, not all macroeconomic factors or conditions are significant in explaining operational efficiency heterogeneity in the short run. Empirical results reported in table 1 for instance, show that in the short run, prevailing inflation (Infl), inflation expectations (InfExp), global market exposure (GME) and lag operational efficiency trend $\left(N I M_{t-1}\right)$ have no statistically significant impact on operational efficiency among US commercial banks. Estimated results presented in table 1 further show that, just as have been found by related studies focusing on effects of modeled factors on bank performance, macroeconomic uncertainty (Munc) tend to have significant negative impact on operational efficiency among commercial banks. For instance, this study finds that percentage deterioration in prevailing macroeconomic environment or economic uncertainty reduces aggregate operational efficiency among commercial banks by approximately $9 \%$ cateris peribus. This condition suggest that macroeconomic uncertainty makes US commercial banks less efficient operationally, possibly due to less informative projections or economic signals. Insignificant effects of inflation expectations on operational efficiency as measured in this study, was also expected in that, if one assumes rationality on the part of such banks then operational activities of commercial banks should normally reflects or capture projected or expected inflationary conditions. If such rational condition holds, then, inflationary expectations should have minimal or no statistically significant impact on operational efficiency; since such expectations would have already been incorporated or factored into present decisions on bank's operations. For instance, according to Bernanke B. (2004), realized inflation tends to mimic prior inflation expectation trajectory; a condition which suggest that realized inflation or prevailing inflationary condition at any point in time does not deviate significantly from projected inflation expectations. Consequently, such expectations might not have significant impact on operational dynamics among commercial banks because the condition would have been incorporated in operational decisions.

Although a segment of related literature provide empirical evidence suggesting that exchange rate fluctuations or volatility could be inimical to bank profitability through its effect on GDP growth, Schnabl (2007) (Note 2); this study finds that in the short run, the condition rather has positive impact on aggregate operational efficiency among US commercial banks. A critical assessment of this outcome suggest that the positive interaction could be explained in part, by the fact that, potential adverse effect of the condition (i.e. exchange rate fluctuations) on profitability might serve as an incentive driving the need for improved operational efficiency. Thus, whereas one may expect such volatile condition to be inimical to profitability, the same cannot be said of its impact on operational efficiency since threat emanating from the condition could engender the need for improved operational efficiency. Coefficient estimate reported in table 1 suggests a percentage increase in exchange rate volatility improves aggregate operational efficiency among US commercial banks by approximately $2.3 \%$ all things being equal. On the other hand, contrary to this study's expectations, reported result on the effects of financial liberalization on aggregate operational efficiency suggests the condition has significant negative impact on operational efficiency. Even though evidence from studies such as Lim (2012), suggested that financial liberalization improves profit condition among banks, it is not clear whether the same condition actually improve operational efficiency among such banks. This study's conclusion, however, is supported to some extent by Yee, Sakinah and Mohamad (2008); who found that financial liberalization could independently exert negative effect on the stability of the banking sector. Thus, the removal or weakening of regulations meant to ensure financial stability has the potential to make commercial banks less efficient in their operations.

Finally, reported short run estimates additionally suggests economic growth, captured as percentage growth in GDP, has significant positive impact on bank operational efficiency. Coefficient estimates indicate a percentage growth in GDP could be responsible for about 3\% growth in operational efficiency among US commercial banks. This outcome further lends credence to the view that sustained economic performance does not only augment profitability as has been found in other related studies; but is also crucial in enhancing operational efficiency among banking institutions; at least at the aggregate level. 


\subsubsection{Operational Efficiency among US Commercial Banks and Macroeconomic Conditions: Long Run Analysis}

Long run coefficient estimates on the extent to which modeled explanatory variables impact aggregate operational efficiency among US commercial banks, differ significantly from short run conditions discussed above. For instance, reported results in table 1 suggest that macroeconomic uncertainty has no statistically significant impact on operational efficiency in the long run; perhaps due to saturation of accommodative operational adjustments made over a period of time. Reported results further suggest that unlike conditions found in the short run, in the long run, global economic exposure or growing integration is significant in explaining variability in bank operational efficiency (in addition to exchange rate volatility, financial liberalization and prevailing inflation). However, the intensity of the effects of modeled variables or conditions in the long run, differ significantly from those reported in the short run. For instance, critical examination of the results suggest that, consistent with results reported in the short run, exchange rate volatility tend to have positive impact on operational efficiency among US commercial banks in the long run; However, actual coefficient estimates suggest that long run effects tend to be more pronounced than in the short run. In both scenarios, our results suggest that growing exchange rate volatility rather necessitate the need for much needed efficiency in banking operations to reduce potential loses; hence the positive effects. Additionally, long run coefficient estimates also show that financial liberalization constrains or has negative impact on commercial bank operational efficiency; a condition similar to earlier findings in the short run. The result on this particular condition suggest that a percentage growth in financial liberalization reduces operational efficiency among such banks by approximately $0.7 \%$ all things being equal; again this negative relationship is consistent with findings reported by Yee, Sakinah and Mohamad (2008).

Empirical evidence reviewed, largely supports negative association between inflationary conditions and bank profitability; and to some extent operational efficiency among commercial banks. For instance, in a study focusing on bank efficiency among Sub-Saharan Africa Middle income economies, Chuling Chen (2009) showed that higher inflationary conditions lower cost efficiency among banks. This conclusion however, only captures a portion of the entire operational efficiency as defined in this study. Contrary to this inverse relationship between inflation and bank cost efficiency, this study finds that percentage growth in inflationary conditions rather augments or has positive impact on the rate of growth in aggregate operational efficiency by as much as $11 \%$. This outcome to some degree, suggest that, commercial banks strives to be more efficient during inflationary conditions-possibly to avoid potential negative impact on profitability. It is also important to point out that, although operational efficiency is integral component in estimating bank profitability, being operationally efficient might not necessarily translate into positive profit margins; consequently, inflationary condition might enhance operational efficiency without necessarily augmenting bank profitability. This conclusion to some degree is consistent with findings by Yong Tan, Christos Floros, (2012), who reported positive association between bank profitability, cost efficiency and inflation in China.

Global market exposure variable (GME), which in this study, captures the extent of exposure of US commercial banks to global macroeconomic dynamics, is also found to have significant impact on operational efficiency in the long run. This study finds that global market integration or exposure can constrain rate of growth in operational efficiency among banks; possibly due to overreliance on external competencies or support. Existing studies investigating effect of global market exposure on bank efficiency diverge significantly. For instance, whereas studies such as Sufian and Habibullah (2012) supports the notion that greater integration of economies fosters greater efficiency among banks due to spillover of cutting edge innovations, competition and improved technologies; other analysts have been skeptical about such conclusion. Critics for instance suggest that growing integration or global market exposure could be inimical to domestic banks due to potential ripple effects of financial distress from other economies. It has also been argued that the extent to which such exposure impacts financial institutions within an economy depend on the strength of the domestic financial sector; a strong financial sector might benefit significantly, whereas a weak one might be vulnerable to external shocks.

\subsubsection{Conclusion}

This study sought to provide insights into how specific macroeconomic conditions and other factors impact operational efficiency among commercial banks. Empirical findings reported in table 1 suggest that among the variables tested, only macroeconomic uncertainty, exchange rate volatility, global market exposure and GDP growth, actually influence operational efficiency among US commercial banks in the short run. For instance, this study finds that GDP growth and exchange rate volatility positively impact aggregate operational efficiency among commercial banks; with a percentage increase in the variables significantly augmenting aggregate operational efficiency. Short run estimates further suggest that macroeconomic uncertainty and financial 
liberalization have negative impact, or constrain growth in operational efficiency among US commercial banks. Additionally, reported coefficient estimates further suggest that effects of some macroeconomic conditions or factors tend to dissipates over time; and consequently, cease to have empirically verifiable impact on bank operational efficiency in the long run. This study for instance, finds that macroeconomic uncertainty does not have empirically verifiable impact on operational efficiency among US commercial banks in the long run though earlier analysis found negative impact in the short run. Again, this study also finds that exchange rate volatility and inflationary conditions positively impact aggregate operational efficiency among US commercial banks in the long run; whereas, financial liberalization and global market exposure constrains its growth. Overall, our findings suggests that a plethora of macroeconomic conditions ultimately culminates in explaining variability in aggregate operational efficiency among US commercial banks; and that, operational efficiency among commercial banks tend to respond differently to similar external or macroeconomic condition in the short and the long run.

\section{References}

Abbasoglu, O. F., Aysan, A. F., \& Gunes, A. (2007). Concentration, competition, efficiency and profitability of the Turkish banking sector in the post-crisis period. Banks and Bank Systems, 2(3), 106-115.

Afanasieff, T., Lhacer, P., \& Nakane, M. (2002). The determinants of bank interest spreads in Brazil. Working Paper. Banco Central di Brazil.

Ahmed, I., \& Qayyum, A. (2007). Do Public Expenditure and Macroeconomic Uncertainty matter to Private Investment Growth? Evidence from Pakistan. The Pakistan Development Review, 46(2), 145-161.

Alam, M. I., \& Quazi, R. M. (2003). Determinant of capital flight: An econometric case study of Bangladesh. International Review of Applied Economics, 17, 85-103. http://dx.doi.org/10.1080/713673164

Al-Hashimi, A. (2007). Determinants of Bank Spreads in Sub-Saharan Africa. IMF Draft Working Paper, 05/06.

Allen, L., \& Saunders, A. (2004). Incorporating Systemic Influences into Risk Measurements: A Survey of the Literature. Journal of Financial Services Research, 26, 161-191. http://dx.doi.org/10.1023/B:FINA.0000037545.38154.8a

Athanasoglou, P. P., Sophocles, N. B., \& Matthaios, D. D. (2005). Bank-specific, industry-specific and macroeconomic determinants of bank profitability. Bank of Greece, 1(1), 3-4.

Ayadi, N., \& Boujelbene, Y. (2012). The Determinants of the Profitability of the Tunisian Deposit Banks. IBIMA Business Review, 1-21. http://dx.doi.org/10.5171/2012.165418

Barros, C., Ferreira, C., \& Williams, J. (2007). Analysing the determinants of performance of best and worst European banks: A mixed logit approach. Journal of Banking \& Finance, 31, 2189-2203. http://dx.doi.org/10.1016/j.jbankfin.2006.11.010

Ben Naceur, S., \& Goaied, M. (2008). The determinants of commercial bank interest margin and profitability: evidence from Tunisia. Frontiers in Finance and Economics, 5, 106-130.

Bernanke, B. (2004). The Economic Outlook and Monetary Policy. Speech at the Bond Market Association Annual Meeting, New York.

Bikker, J., \& Hu, H. (2002). Cyclical Patterns in Profits, Provisioning and Lending of Banks and Procyclicality of the New Basel Capital Requirements. BNL Quarterly Review, 221, 143-175.

Bollerslev, T. (1986). Generalized Autoregressive Conditional Heteroskedasticity. Journal of Econometrics, 31, 307-327. http://dx.doi.org/10.1016/0304-4076(86)90063-1

Chen, C. (2009). Bank Efficiency in Sub-Saharan African Middle-Income Countries. International Monetary Fund Working Paper; WP/09/14.

Demirgüç-Kunt, A., \& Huizinga, H. (1999). Determinants of commercial bank interest margins and profitability: Some international evidence. The World Bank Economic Review, 13(2), 379-408. http://dx.doi.org/10.1093/wber/13.2.379

Dietrich, A., \& Wanzenried, G. (2011). Determinants of bank profitability before and during the crisis: Evidence from Switzerland. J. Int. Finance.

Engle, R. F. (1982). Autoregressive Conditional Heteroscedasticity with Estimates of the Variance of United Kingdom Inflation. Econometrica, 50(4), 987-1007. http://dx.doi.org/10.2307/1912773

Fedzlan, S., \& Royfaizal, R. (2008). Determinants of Bank Profitability in a Developing Economy: Empirical 
Evidence from the Philipinnes. Asian Academy of Management Journal of Accounting and Finance, 4(2), 91-112.

Filbeck, G., Preece, D., \& Zhao, X. (2011). Top Performing Banks: Size Effect and Economic Cycles. Journal of Investing, 20, 19-32. http://dx.doi.org/10.3905/joi.2011.20.1.019

Gul, S., Faiza, I., \& Khalid, Z. (2011). Factors Affecting Bank Profitability in Pakistan. The Romanian Economic Journal, 2(3), 6-9.

Kasman, A. (2010). Consolidation and Commercial bank net interest margins: evidence from the old and new European Union members and candidate countries. Economic Modeling, 27, $648-655$. http://dx.doi.org/10.1016/j.econmod.2010.01.004

Kosmidou, K. (2008). The determinants of banks' profits in Greece during the period of EU financial integration. Managerial Finance, 34(3), 146-159. http://dx.doi.org/10.1108/03074350810848036

Lim, E. (2012). A Study On Credit Interest Margin And Efficiency Ratios Of Selected Universal Banks In The Philippines For The Year 2010. International Journal of Information Technology and Business Management, 2(1)

Liu, H., \& Wilson, J. O. S. (2010). The profitability of banks in Japan. Applied Financial Economics, 20(24), 1851-1866. http://dx.doi.org/10.1080/09603107.2010.526577

Micco, A., Panizza, U., \& Yanez, M. (2007). Bank ownership and performance. Does politics matter? Journal of Banking and Finance, 31(1), 219-241. http://dx.doi.org/10.1016/j.jbankfin.2006.02.007

Millar, L. (2005). The measurement and determinants of UK banks'performance. Cass Business School Past Dissertation, available from the Cyril Kleinwort Learning Resource Centre, Cass Business School.

Molyneux, P., \& Thornton, J. (1992). Determinants of European Bank Profitability: A Note. Journal of Banking and Finance, 16(6), 1173-1178. http://dx.doi.org/10.1016/0378-4266(92)90065-8

Narayan, P. K. (2004). Reformulating critical values for the bounds F-statistics approach to cointegration: An application to the tourism demand model for Fiji. Department of Economics Discussion Papers, No. 02/04, Monash University, Melbourne.

Panayiotis, P., Anthanasoglou, S., Brissimis, N., \& Mathaios, D. D. (2005). Bank Specific, Industry-Specific and Macroeconomic Determinants of Bank Profitability. Bank of Greece Working Paper, 25.

Pasiouras, F., \& Kosmidou, K. (2007). Factors influencing the profitability of domestic and foreign commercial banks in the European Union. Research in International Business and Finance, 21(2), 222-237. http://dx.doi.org/10.1016/j.ribaf.2006.03.007

Pesaran, M. H., Shin, Y., \& Smith, R. J. (2001). Bounds testing approaches to the analysis of level relationships. Journal of Applied Econometrics, 16, 289-326. http://dx.doi.org/10.1002/jae.616

Phillips, P., \& Perron, P. (1988). Testing for a unit root in time series regression. Biometrica, 75, 335-346. http://dx.doi.org/10.1093/biomet/75.2.335

Saunders, A., \& Schumacher, L. (2000). The determinants of bank interest rate margins: an international study. Journal of International Money and Finance, 19(6), 813-832. http://dx.doi.org/10.1016/S0261-5606(00)00033-4

Schnabl, G. (2007). Exchange Rate Volatility and Growth in Small Open Economies at the EMU Periphery. European Central Bank, Working Paper Series, NO 773.

Schwaiger, M. S., \& Liebig, D. (2008). Determinants of bank interest margins in Central and Eastern Europe. Financial Stability Report, 14, 68-87.

Stiroh, K. J., \& Rumble, A. (2006). The dark side of diversification: The case of US financial holding companies. Journal of Banking and Finance, 30, 2131-2161. http://dx.doi.org/10.1016/j.jbankfin.2005.04.030

Stoughton, N. M., \& Zechner, J. (2007). Optimal Capital Allocation using RAROC and EVA. Journal of Financial Intermediation, 16, 312-342. http://dx.doi.org/10.1016/j.jfi.2006.12.004

Sufian, F., \& Habibullah, M. S. (2012). Review of Development Finance, 2, $139-155$. http://dx.doi.org/10.1016/j.rdf.2012.09.003

Toddard, J., Molneux, P., \& Wilson, J. O. S. (2004). Dynamics of Growth and Profitability in Banking. Ohio State University. Journal of Money, Credit, and Banking, 36(6). 
Vensel, V., Aarma, A., \& Vainu, J. (2004). Bank Performance Analysis: Methodology and Empirical Evidence: Estonian Banking System, 1994-2002. Working Paper Series.

Yee, C. F., Sakinah, S., \& Mohamad, M. (2008). Financial Liberalization and the Malaysian Banking Sector: Some Statistical Evidence. Retrieved from http://www.apeaweb.org/confer/hk10/papers/yee_cf.pdf

Yong, T., \& Christos, F. (2012). Bank profitability and inflation: the case of China. Journal of Economic Studies, 39(6), 675-696. http://dx.doi.org/10.1108/01443581211274610

\section{Notes}

Note 1 . To be reviewed in subsequent sections.

Note 2. This study found robust evidence suggesting that exchange rate stability is associated with substantial growth in the European Monetary Unit (EMU) and vice versa.

\section{Copyrights}

Copyright for this article is retained by the author(s), with first publication rights granted to the journal.

This is an open-access article distributed under the terms and conditions of the Creative Commons Attribution license (http://creativecommons.org/licenses/by/3.0/). 